Arq. Bras. Med. Vet. Zootec., v.63, n.3, p.624-632, 2011

\title{
Altos níveis de fitase em rações para frangos de corte
}

[High levels of phytase in diets for broilers]

\author{
C. Meneghetti, A.G. Bertechini, P.B. Rodrigues, E.J. Fassani, J.A.G. Brito, \\ M.P. Reis, A.A.P. Garcia Jr
}

Universidade Federal de Lavras -UFLA

Departamento de Zootecnia

Campus Universitário s/n

37200-00 Lavras, MG

\begin{abstract}
RESUMO
Avaliaram-se o desempenho, o coeficiente de digestibilidade da matéria seca (CDMS), da proteína bruta (CDPB), a retenção aparente de cálcio $(\mathrm{Ca})$ e fósforo $(\mathrm{P})$ e a energia metabolizável aparente corrigida para balanço de nitrogênio (EMAn) de dietas suplementadas com altos teores de fitase (FTU) para frangos, até 35 dias de idade. Foram utilizados 1848 pintos, distribuídos em delineamento inteiramente ao acaso, com sete tratamentos e oito repetições de 35 aves. Os tratamentos foram: T1: dieta-controle; T2: dieta com inclusão de 1.500FTU/kg; T3: 3.000FTU/kg; T4: 4.500FTU/kg; T5: 6.000FTU/kg; T6: 8.000FTU/kg e T7: $10.000 \mathrm{FTU} / \mathrm{kg}$ de ração. No $10^{\circ}$ e $28^{\circ}$ dias de experimento, quatro e três aves, respectivamente, foram transferidas para gaiolas de metabolismo. A partir da inclusão de 4.500FTU/kg, o desempenho das aves de 1 a 35 dias foi semelhante ao das aves do grupo-controle $(\mathrm{P}>0,05)$. Não houve diferença $(\mathrm{P}>0,05)$ entre os tratamentos nos CDPB e nos valores de EMAn, porém, na fase inicial, observou-se maior aproveitamento da MS com os altos níveis de fitase $(\mathrm{P}<0,05)$. Em relação à retenção de Ca e P, houve efeito positivo da suplementação enzimática, com aumento significativo do uso desses minerais pelas aves. Concluiu-se que é possível suplementar altos teores de fitase valorando adequadamente os nutrientes da dieta.
\end{abstract}

Palavras-chave: frango, fitato, desempenho, metabolismo, redução nutricional

\begin{abstract}
The digestibility of dry matter (DMD), and of crude protein (CPD), the apparent retention of calcium $(C a)$ and phosphorus $(P)$ and apparent metabolizable energy corrected by nitrogen balance (AME) of diets supplemented with high levels of phytase (FTU) for broilers, 35 days old were evaluated. A total of 1848 chicks were distributed in a completely randomized experiment with seven treatments and eight repetitions. The treatments were: T1: control diet, T2: inclusion of 1,500FTU/kg; T3: 3,000FTU/kg; T4: 4,500FTU/kg; T5: 6,000FTU/kg; T6:8,000FTU/kg; and T7: 10,000FTU/kg feed. On the 10th and 28th days of the experiment, four and three birds, respectively, were transferred to metabolism cages. An addition of 4,500FTU/kg from 1 to 35 days resulted in a performance similar to the control group $(P>0.05)$. There was no difference $(P>0.05)$ among treatments for DMD and AME, however, during the initial phase there was a higher use of $M S$ with high levels of phytase $(P<0.05)$. Regarding the retention of $\mathrm{Ca}$ and $\mathrm{P}$, a positive effect of enzyme supplementation significantly increased the use of these minerals by birds. It is possible that high levels of supplemental phytase adequate valuing the nutrients.
\end{abstract}

Keywords: broiler, phytate, performance, metabolism, nutrition reducion

Recebido em 25 de março de 2010

Aceito em 13 de abril de 2011

E-mail: cameneghetti@yahoo.com.br 


\section{INTRODUÇÃO}

Entre as enzimas exógenas produzidas industrialmente, a fitase é a que mais se destaca, em virtude da magnitude e da consistência relativamente altas da bioeficácia dessa enzima e do aumento dos custos dos ingredientes e da fabricação das rações, além da legislação de alguns países associada à poluição ambiental.

Efetivamente, a fitase é uma alternativa econômica para melhorar a disponibilidade do fósforo fítico, forma complexada nos ingredientes vegetais e que não é utilizado pelas aves. Segundo alguns relatos da literatura (Mullaney et al., 2000), as reservas de fósforo que não são renováveis, em médio prazo, deverão estar escassas. Estima-se que cerca de 14,4 milhões de toneladas de fósforo fítico são produzidos anualmente no mundo nas colheitas de grãos/sementes e frutas, número que representaria $65 \%$ nas vendas de fertilizantes fosfatados em todo o mundo (Lott et al., 2000).

A molécula de ácido fítico contém aproximadamente $28,2 \%$ de fósforo e possui propriedade antinutricional pelo não aproveitamento do fósforo, além de complexarse com proteínas, aminoácidos, cátions, amido e enzimas, como a pepsina, tripsina, alfa-amilase e cofatores de enzimas (Ravindran et al., 1999; Angel et al., 2002; Cowieson et al., 2006; Selle e Ravindran, 2007). Dessa forma, a solubilidade e a digestibilidade da dieta são drasticamente reduzidas pela formação de complexos insolúveis entre o ácido fítico e as substâncias citadas acima.

O teor preconizado de fitase (FTU) pela indústria, em dietas para frangos de corte, foi de $500 \mathrm{FTU} / \mathrm{kg}$ de dieta, o qual libera, em média, 0,1\% de fósforo disponível (Pd) (Dari, 2004). Porém, o preço da enzima, atualmente, permite maior inclusão como estratégia nutricional para reduzir a inclusão de certos ingredientes, diminuir o custo de formulação e, consequentemente, reduzir a excreção de poluentes ao ambiente. Embora alguns trabalhos (Shirley e Edwards Junior, 2003; Manangi e Coon, 2008) demonstrem ótimos resultados com teores acima de $1.000 \mathrm{FTU} / \mathrm{kg}$ em dietas de aves, são necessários mais estudos neste sentido para adequar matrizes nutricionais que possam contribuir para manter o bom desempenho das aves.

Este experimento teve como objetivo avaliar o efeito da inclusão de altos teores de uma fitase bacteriana em dietas com redução nutricional, para frangos de corte até 35 dias de idade, sobre o desempenho, a digestibilidade aparente da matéria seca e da proteína bruta, a retenção aparente de cálcio e fósforo e a energia metabolizável corrigida para balanço de nitrogênio.

\section{MATERIAL E MÉTODOS}

Foram utilizados 1848 pintos de um dia, Cobb500, provenientes de incubatório comercial, com peso médio de 45,3g, alojados em galpão convencional de alvenaria, distribuídos em 56 boxes até 35 dias de idade. Simultaneamente ao ensaio de desempenho, no $10^{\circ}$ e $28^{\circ}$ dias de experimento, quatro e três aves, respectivamente, de cada boxe, foram transferidas para gaiolas de metabolismo, providas de bebedouros e comedouros tipo calha.

O delineamento foi inteiramente ao acaso, com sete tratamentos e oito repetições em cada ensaio. Os tratamentos experimentais foram constituídos de seis níveis de inclusão de fitase 1.500, 3.000, 4.500, 6.000, 8.000 e 10.000FTU/kg de ração - e uma dieta denominada controle, sem suplementação enzimática.

Todas as rações que continham fitase tiveram redução nutricional e, de acordo com as recomendações da indústria e os resultados da literatura, na fase inicial - de 1 a 21 dias de criação -, a redução foi de $45 \%$ de fósforo disponível $(0,2) ; 16 \%$ de cálcio $(0,15) ; 4 \%$ de proteína bruta $(\sim 0,8) ; 3,6 \%$ de metionina, lisina, treonina e triptofano e, aproximadamente, 2,5\% de energia metabolizável aparente corrigida para balanço de nitrogênio (EMAn) (85kcal/kg). Na fase de crescimento, as reduções foram menores, o que é explicado pela diminuição da inclusão do farelo de soja, responsável pelo substrato (ácido fítico) da fitase nas dietas experimentais. As reduções foram: $42 \%$ de fósforo disponível $(0,18) ; 16 \%$ de cálcio $(0,15) ; 3 \%$ de proteína bruta $(\sim 0,6) ; 2,7 \%$ nos quatro primeiros aminoácidos limitantes e, aproximadamente, 2\% de EMAn (60kcal/kg). 
As dietas experimentais, da fase inicial - de 1 a 21 dias - (Tab. 1) e de crescimento - de 1 a 35 dias - (Tab. 2), foram à base de milho e farelo de soja, formuladas de acordo com as recomendações nutricionais de (Cobb-Vantress... 2004). A composição, em nutrientes, dos principais alimentos usados na formulação foi obtida nas tabelas brasileiras (Rostagno et al., 2005), e a fitase utilizada foi uma 6-fitase, com origem nos microrganismos Citrobacter braakii e Escherichia coli, distribuída pela Comércio e Indústria Uniquímica Ltda.

As pesagens das aves foram efetuadas no $1^{\circ}, 21^{\circ}$ e $35^{\circ}$ dias de idade das aves. O controle do consumo de ração foi realizado com a pesagem das sobras em cada período. A mortalidade foi monitorada diariamente para cálculo da viabilidade de criação e correção do consumo e da conversão alimentar.

Tabela 1. Composição percentual e nível nutricional calculado das dietas experimentais para frangos de corte na fase inicial de criação (1-21dias)

\begin{tabular}{|c|c|c|c|c|c|c|c|}
\hline Ingrediente & Controle & $\begin{array}{l}1500 \\
\text { FTU } \\
\end{array}$ & $\begin{array}{c}3.000 \\
\text { FTU } \\
\end{array}$ & $\begin{array}{l}4.500 \\
\text { FTU } \\
\end{array}$ & $\begin{array}{c}6.000 \\
\text { FTU } \\
\end{array}$ & $\begin{array}{c}8.000 \\
\text { FTU } \\
\end{array}$ & $\begin{array}{c}10.000 \\
\text { FTU }\end{array}$ \\
\hline Milho & 52,410 & 58,769 & 58,742 & 58,711 & 58,672 & 58,636 & 58,592 \\
\hline Farelo de soja & 40,018 & 37,093 & 37,096 & 37,102 & 37,111 & 37,118 & 37,125 \\
\hline Óleo de soja & 3,700 & 1,038 & 1,047 & 1,058 & 1,07 & 1,082 & 1,097 \\
\hline Fosfato bicálcico & 1,867 & 0,757 & 0,756 & 0,756 & 0,758 & 0,757 & 0,757 \\
\hline Calcário calcítico & 0,863 & 1,172 & 1,172 & 1,173 & 1,171 & 1,171 & 1,172 \\
\hline Sal comum & 0,389 & 0,388 & 0,388 & 0,388 & 0,388 & 0,388 & 0,388 \\
\hline Suplemento vitamínico ${ }^{1}$ & 0,100 & 0,100 & 0,100 & 0,100 & 0,100 & 0,100 & 0,100 \\
\hline Suplemento mineral $^{2}$ & 0,100 & 0,100 & 0,100 & 0,100 & 0,100 & 0,100 & 0,100 \\
\hline DL-metionina (99\%) & 0,257 & 0,241 & 0,241 & 0,241 & 0,241 & 0,241 & 0,241 \\
\hline L-lisina $(78 \%)$ & 0,051 & 0,081 & 0,08 & 0,081 & 0,081 & 0,080 & 0,080 \\
\hline L-treonina (99\%) & 0 & 0,003 & 0,003 & 0,003 & 0,003 & 0,003 & 0,003 \\
\hline Cl-colina (70\%) & 0,057 & 0,057 & 0,057 & 0,057 & 0,057 & 0,057 & 0,057 \\
\hline Salinomicina (12\%) & 0,050 & 0,050 & 0,050 & 0,050 & 0,050 & 0,050 & 0,050 \\
\hline Bacitracina de Zn (10\%) & 0,025 & 0,025 & 0,025 & 0,025 & 0,025 & 0,025 & 0,025 \\
\hline Sulfato de colistina (8\%) & 0,0125 & 0,0125 & 0,0125 & 0,0125 & 0,0125 & 0,0125 & 0,0125 \\
\hline Bicarbonato de sódio & 0,100 & 0,100 & 0,100 & 0,100 & 0,100 & 0,100 & 0,100 \\
\hline Fitase $^{3}$ & 0 & 0,015 & 0,030 & 0,045 & 0,060 & 0,080 & 0,100 \\
\hline Total & 100 & 100 & 100 & 100 & 100 & 100 & 100 \\
\hline EMAn (kcal/kg) ${ }^{4}$ & 3000 & 2915 & 2915 & 2915 & 2915 & 2915 & 2915 \\
\hline Proteína Bruta (\%) & 22,465 & 21,665 & 21,665 & 21,665 & 21,665 & 21,665 & 21,665 \\
\hline Lisina digestível (\%) & 1,170 & 1,132 & 1,132 & 1,132 & 1,132 & 1,132 & 1,132 \\
\hline Metionina + cistína dig. (\%) & 0,870 & 0,842 & 0,842 & 0,842 & 0,842 & 0,842 & 0,842 \\
\hline Treonina digestível (\%) & 0,770 & 0,744 & 0,744 & 0,744 & 0,744 & 0,744 & 0,744 \\
\hline Cálcio (\%) & 0,900 & 0,750 & $0, \mathrm{~m} 750$ & 0,750 & 0,750 & 0,750 & 0,750 \\
\hline Fósforo disponível (\%) & 0,450 & 0,250 & 0,250 & 0,250 & 0,250 & 0,250 & 0,250 \\
\hline Fósforo total (\%) & 0,674 & 0,474 & 0,474 & 0,474 & 0,474 & 0,474 & 0,474 \\
\hline Sódio (\%) & 0,200 & 0,200 & 0,200 & 0,200 & 0,200 & 0,200 & 0,200 \\
\hline
\end{tabular}

${ }^{1}$ Enriquecimento por kg de ração: Vit. A - 12.000UI, Vit. $\mathrm{D}_{3}-2.200$, Vit. E - 30mg, Vit. K - 2,5mg, Niacina - 53mg,

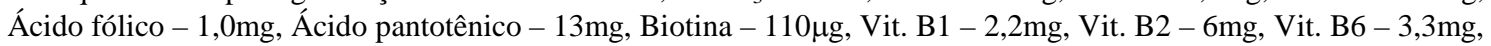

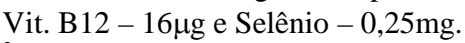

${ }^{2}$ Enriquecimento de minerais por kg de ração: Ferro - 50mg; Cobre 8,5mg; Zinco - 70mg; Manganês - 75mg; Iodo 1,5mg e Cobalto - 0,2mg.

${ }^{3}$ Comercialmente denominada Genophos ${ }^{\circledR}$, com atividade de $10.000 \mathrm{FTU} / \mathrm{g}$.

${ }^{4}$ EMAn: energia metabolizável corrigida para balanço de nitrogênio (kcal/kg). 
Altos níveis de fitase...

Tabela 2. Composição percentual e nível nutricional calculado das dietas experimentais para frangos de corte na fase de crescimento (22-35dias)

\begin{tabular}{|c|c|c|c|c|c|c|c|}
\hline Ingrediente & Controle & $\begin{array}{c}1.500 \\
\text { FTU }\end{array}$ & $\begin{array}{c}3.000 \\
\text { FTU }\end{array}$ & $\begin{array}{c}4.500 \\
\text { FTU }\end{array}$ & $\begin{array}{c}6.000 \\
\text { FTU }\end{array}$ & $\begin{array}{c}8.000 \\
\text { FTU }\end{array}$ & $\begin{array}{c}10.000 \\
\text { FTU }\end{array}$ \\
\hline Milho & 58,630 & 63,490 & 63,473 & 63,431 & 63,395 & 63,357 & 63,313 \\
\hline Farelo de soja & 33,445 & 31,325 & 31,325 & 31,333 & 31,341 & 31,348 & 31,356 \\
\hline Óleo de soja & 4,132 & 2,130 & 2,136 & 2,151 & 2,162 & 2,175 & 2,190 \\
\hline Fosfato bicálcico & 1,738 & 0,737 & 0,737 & 0,737 & 0,739 & 0,738 & 0,738 \\
\hline Calcário calcítico & 0,926 & 1,164 & 1,164 & 1,165 & 1,163 & 1,163 & 1,164 \\
\hline Sal comum & 0,314 & 0,313 & 0,313 & 0,313 & 0,313 & 0,313 & 0,313 \\
\hline Suplemento vitamínico ${ }^{1}$ & 0,100 & 0,100 & 0,100 & 0,100 & 0,100 & 0,100 & 0,100 \\
\hline Suplemento mineral $^{2}$ & 0,100 & 0,100 & 0,100 & 0,100 & 0,100 & 0,100 & 0,100 \\
\hline DL-metionina (99\%) & 0,250 & 0,237 & 0,237 & 0,238 & 0,238 & 0,238 & 0,238 \\
\hline L-lisina (78\%) & 0,082 & 0,105 & 0,104 & 0,104 & 0,104 & 0,104 & 0,104 \\
\hline L-treonina (99\%) & 0,027 & 0,029 & 0,029 & 0,029 & 0,029 & 0,029 & 0,029 \\
\hline Cl-colina (70\%) & 0,043 & 0,043 & 0,043 & 0,043 & 0,043 & 0,043 & 0,043 \\
\hline Salinomicina (12\%) & 0,050 & 0,050 & 0,050 & 0,050 & 0,050 & 0,050 & 0,05 \\
\hline Bacitracina Zn (10\%) & 0,050 & 0,050 & 0,050 & 0,050 & 0,050 & 0,050 & 0,050 \\
\hline Sulf. colistina (8\%) & 0,0125 & 0,0125 & 0,0125 & 0,0125 & 0,0125 & 0,0125 & 0,0125 \\
\hline Bicarbonato de sódio & 0,100 & 0,100 & 0,100 & 0,100 & 0,100 & 0,100 & 0,100 \\
\hline Fitase $^{3}$ & 0 & 0,015 & 0,030 & 0,045 & 0,060 & 0,080 & 0,100 \\
\hline Total & 100 & 100 & 100 & 100 & 100 & 100 & 100 \\
\hline EMAn (kcal/kg) $^{4}$ & 3100 & 3040 & 3040 & 3040 & 3040 & 3040 & 3040 \\
\hline Proteína bruta (\%) & 20,000 & 19,440 & 19,440 & 19,440 & 19,440 & 19,440 & 19,440 \\
\hline Lisina digestível (\%) & 1,040 & 1,013 & 1,013 & 1,013 & 1,013 & 1,013 & 1,013 \\
\hline $\begin{array}{l}\text { Metionina }+ \\
\text { digestível (\%) }\end{array}$ & 0,810 & 0,791 & 0,791 & 0,791 & 0,791 & 0,791 & 0,791 \\
\hline Treonina digestível (\%) & 0,710 & 0,692 & 0,692 & 0,692 & 0,692 & 0,692 & 0,692 \\
\hline Cálcio (\%) & 0,880 & 0,730 & 0,730 & 0,730 & 0,730 & 0,730 & 0,730 \\
\hline Fósforo disponível (\%) & 0,420 & 0,240 & 0,240 & 0,240 & 0,240 & 0,240 & 0,240 \\
\hline Fósforo total (\%) & 0,631 & 0,451 & 0,451 & 0,451 & 0,451 & 0,451 & 0,451 \\
\hline Sódio (\%) & 0,170 & 0,170 & 0,170 & 0,170 & 0,170 & 0,170 & 0,170 \\
\hline
\end{tabular}

${ }^{1}$ Enriquecimento por kg de ração: Vit.A - 12.000UI, Vit.D - 2.200, Vit E - 30mg, Vit. K - 2,5mg, Niacina - 53mg,

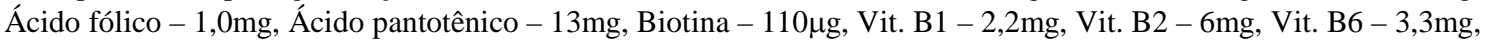

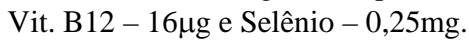

${ }^{2}$ Enriquecimento de minerais por kg de ração: Ferro - 50mg; Cobre 8,5mg; Zinco - 70mg; Manganês - 75mg; Iodo 1,5mg e Cobalto - 0,2mg;

${ }^{3}$ Comercialmente denominada Genophos ${ }^{\circledR}$, com atividade de $10.000 \mathrm{FTU} / \mathrm{g}$.

${ }^{4}$ EMAn: energia metabolizável corrigida pra balanço de nitrogênio (kcal/kg).

Para o ensaio metabólico, foi utilizado o método de coleta total de excretas, com quatro dias de adaptação e três dias de coleta (Rodrigues et al., 2005). As rações foram marcadas com óxido de ferro para iniciar a coleta, que aconteceu às oito e às $16 \mathrm{~h}$ nos três dias consecutivos. As excretas coletadas diariamente foram acondicionadas em sacos plásticos e armazenadas em freezer até o final do período. Posteriormente, foram, descongeladas, homogeneizadas, pesadas, e alíquotas foram retiradas para secagem em estufas de circulação de ar a $55^{\circ} \mathrm{C}$, até peso constante; em seguida, moídas e acondicionadas para posteriores análises laboratoriais. As metodologias utilizadas para as análises de excretas e rações foram descritas por Silva e Queiroz (2002).

A análise de estatística foi realizada por meio do software Sistema de Análise de Variância, para dados balanceados, descrito por Ferreira (2000). Todos os tratamentos com fitase foram comparados com o tratamento controle pelo teste Dunnett ( $\alpha=5 \%)$, e a açãdiado teor de inclusão de fitase foi feita por análise de regressão, quando significativo. 


\section{RESULTADOS E DISCUSSÃO}

Os valores médios do consumo de ração (CR), ganho de peso (GP) e conversão alimentar (CA) das aves até 21 dias encontram-se na Tab. 3. O CR foi afetado apenas quando as aves receberam dieta com fitase a partir de 4.500FTU/kg
$(\mathrm{P}<0,05)$. Entretanto, essa diferença não foi significativa quanto ao GP $(\mathrm{P}>0,05)$, embora as aves alimentadas com $1.500, \quad 3.000$ e $6.000 \mathrm{FTU} / \mathrm{kg}$ apresentassem os piores valores de CA em relação às do tratamento controle $(\mathrm{P}<0,05)$.

Tabela 3. Consumo de ração (CR), ganho de peso (GP) e conversão alimentar (CA) de frangos de corte na fase de 1 a 21 dias, submetidos a dietas com diferentes teores de fitase

\begin{tabular}{lccc}
\multicolumn{1}{r}{ Tratamento } & CR (g/ave) & GP (g/ave) & CA (g/g) \\
\hline Controle $^{1}$ & 1210 & 856 & 1,415 \\
$1.500 \mathrm{FTU} / \mathrm{kg}$ & 1236 & 842 & $1,468^{*}$ \\
$3.000 \mathrm{FTU} / \mathrm{kg}$ & 1243 & 848 & $1,467^{*}$ \\
$4.500 \mathrm{FTU} / \mathrm{kg}$ & $1258^{*}$ & 870 & 1,447 \\
$6.000 \mathrm{FTU} / \mathrm{kg}$ & $1264^{*}$ & 868 & $1,456^{*}$ \\
$8.000 \mathrm{FTU} / \mathrm{kg}$ & $1253^{*}$ & 864 & 1,451 \\
$10.000 \mathrm{FTU} / \mathrm{kg}$ & $1255^{*}$ & 868 & 1,446 \\
Média & 1246 & 859 & 1,449 \\
CV, \% & 2,70 & 2,79 & 1,92 \\
\hline
\end{tabular}

*Média diferente estatisticamente do tratamento controle, pelo teste de Dunnett ao nível de 5\% de probabilidade.

'Sem suplementação enzimática.

Estes resultados diferem dos encontrados por Shirley e Edwards Junior (2003), que investigaram a suplementação de altos níveis de fitase $(95,75$ a $12.000 \mathrm{FTU} / \mathrm{kg}$ de ração), em rações para frangos de corte, e não observaram diferença no consumo de ração e no ganho de peso a partir da inclusão de $1.500 \mathrm{FTU} / \mathrm{kg}$. A conversão alimentar não diferiu entre os tratamentos, independentemente do teor de fitase.

Possivelmente, a diminuição de 2,6\% na inclusão de óleo nas rações suplementadas com fitase pode ter sido responsável pelos piores valores de conversão alimentar nos tratamentos com 1.500 , 3.000 e $6.000 \mathrm{FTU} / \mathrm{kg}$, em relação ao controle. Pucci et al. (2003) constataram melhora na conversão alimentar de frangos de corte, na fase inicial, quando o óleo de soja foi adicionado às rações, atingindo um platô na inclusão de 2,18\% de óleo. A máxima digestibilidade do extrato etéreo foi observada com a inclusão de 2,33\%, evidenciando, em razão destes resultados, o efeito extracalórico do óleo na conversão alimentar das aves.
$\mathrm{O}$ efeito da fitase em dietas com $\mathrm{P}$ abaixo das exigências tem mostrado ser consistente em manter o desempenho de frangos de corte, e, de acordo com Selle e Ravindran (2007), a magnitude das respostas pode ser mais pronunciada, aumentando-se os níveis de inclusão, em virtude de uma degradação maior do fitato. Entretanto, no presente trabalho, esta resposta não foi observada no ganho de peso e na conversão alimentar dos frangos, que apresentaram valores semelhantes ou piores que o tratamento controle.

Os resultados de desempenho na fase de 22 a 35 dias estão apresentados na Tab. 4. As dietas suplementadas com fitase não influenciaram nenhuma das variáveis estudadas $(\mathrm{P}>0,05)$. Este fato pode ter ocorrido em razão do ganho compensatório das aves. Frangos modernos são hiperfágicos, e o controle no consumo de ração na fase de crescimento por aspectos nutricionais é minimizado em relação à fase inicial. 
Tabela 4. Consumo de ração (CR), ganho de peso (GP) e conversão alimentar (CA) dos frangos de corte, na fase de 22 a 35 dias, submetidos a dietas com diferentes teores de fitase

\begin{tabular}{lccc}
\multicolumn{1}{r}{ Tratamento } & CR (g/ave) & GP (g/ave) & CA (g/g) \\
\hline Controle $^{1}$ & 1994 & 1133 & 1,759 \\
$1.500 F T U / k g$ & 2018 & 1106 & 1,828 \\
$3.000 F T U / k g$ & 1987 & 1087 & 1,830 \\
$4.500 F T U / k g$ & 2012 & 1138 & 1,770 \\
$6.000 F T U / k g$ & 2039 & 1127 & 1,806 \\
$8.000 F T U / k g$ & 2014 & 1123 & 1,794 \\
$10.000 F T U / k g$ & 2007 & 1126 & 1,787 \\
Média & 2010 & 1120 & 1,796 \\
CV, \% & 2,76 & 3,90 & 3,95 \\
\hline$(P>0$ (05) & & &
\end{tabular}

$(\mathrm{P}>0,05)$

'Sem suplementação enzimática.

Entretanto, ao se analisar a fase total - de 1 a 35 dias - (Tab. 5), apesar de não ter havido influência do teor de fitase sobre o consumo de ração e o ganho de peso, observa-se pior resposta na conversão alimentar das aves que consumiram ração suplementada com 1.500 e $3.000 \mathrm{FTU} / \mathrm{kg}$ $(\mathrm{P}<0,05)$. A partir desses resultados, pode-se considerar que a suplementação de fitase a partir de 4.500FTU/kg contribuiu para disponibilizar os nutrientes da dieta nas quantidades necessárias para manter o desempenho adequado dos frangos, quando comparado ao do grupocontrole. Porém, nota-se efeito residual dos tratamentos aplicados na fase inicial de criação.

Tabela 5. Consumo de ração (CR), ganho de peso (GP) e conversão alimentar (CA) dos frangos de corte na fase de 1 a 35 dias, submetidos a dietas com diferentes teores de fitase

\begin{tabular}{lccc}
\multicolumn{1}{r}{ Tratamento } & CR (g/ave) & GP (g/ave) & CA (g/g) \\
\hline Controle $^{1}$ & 3210 & 1993 & 1,611 \\
$1.500 F T U / k g$ & 3259 & 1949 & $1,672^{*}$ \\
$3.000 F T U / k g$ & 3227 & 1933 & $1,670^{*}$ \\
$4.500 F T U / k g$ & 3269 & 2009 & 1,628 \\
$6.000 F T U / k g$ & 3304 & 1989 & 1,661 \\
8.000FTU/kg & 3267 & 1987 & 1,644 \\
$10.000 F T U / k g$ & 3262 & 1994 & 1,638 \\
Média & 3257 & 1979 & 1,646 \\
CV, \% & 2,39 & 2,69 & 2,50 \\
\hline
\end{tabular}

*Média diferente estatisticamente do tratamento controle, pelo teste Dunnett, a 5\% de probabilidade.

${ }^{1}$ Sem suplementação enzimática.

Os resultados encontrados diferem, quanto ao desempenho, dos encontrados por Manangi e Coon (2008), que verificaram aumento no consumo de ração por frangos de corte alimentados com uma dieta basal $(0,7 \% \mathrm{Ca}$; $0,4 \%$ Pt e 0,12 Pd), suplementada com 250, 500, $750,1.000,1.500,2.000$ e $5.000 \mathrm{FTU} / \mathrm{kg}$ de fitase. $\mathrm{O}$ ganho de peso e a conversão alimentar foram melhores com os níveis crescentes de fitase, em relação ao grupo sem suplementação enzimática. Por outro lado, Fukayama et al. (2008) não encontraram diferença no consumo e na conversão alimentar entre frangos de corte alimentados com uma ração contendo $3.000 \mathrm{kcal} / \mathrm{kg}$ de EM e aqueles que consumiram ração formulada com $2940 \mathrm{kcal} / \mathrm{kg}$ de EM e suplementada com fitase (500, 750 e $1.000 \mathrm{FTU} / \mathrm{kg}$ ). Esses autores observaram, também, melhora no ganho de peso das aves.

Os resultados dos coeficientes de digestibilidade aparente da matéria seca (CDAMS), da proteína bruta (CDAPB) e da energia metabolizável aparente corrigida para balanço de nitrogênio (EMAn) das fases inicial e de crescimento encontram-se na Tab. 6. Observa-se que houve 
aumento $(\mathrm{P}<0,05)$ na digestibilidade da matéria seca em todos os tratamentos com fitase, mostrando-se sensível à suplementação de altos níveis, na fase inicial de criação. O CDAPB e o resultado de EMAn não mostraram diferenças significativas entre o tratamento controle
$(\mathrm{P}>0,05)$ e o tratamento com fitase. Na fase seguinte (22 a 35 dias), não houve diferença significativa $(\mathrm{P}>0,05)$ em nenhuma dessas características avaliadas, entre os tratamentos suplementados com fitase e o controle.

Tabela 6. Coeficientes de digestibilidade aparente (CDAMS, \%) da matéria seca, da proteína bruta (CDAPB, \%) e da energia metabolizável aparente (EMAn, kcal/kg de MS) corrigida para balanço de nitrogênio das dietas com diferentes teores de fitase, para frangos de corte nas fases inicial, de 1 a 21 dias, e de crescimento, de 22 a 35 dias

\begin{tabular}{lcccccc}
\hline & \multicolumn{3}{c}{ Fase inicial } & \multicolumn{3}{c}{ Fase de crescimento } \\
\cline { 2 - 6 } Tratamento & CDAMS & CDAPB & EMAn $^{2}$ & CDAMS & CDAPB & EMAn \\
\hline Controle $^{1}$ & 71,45 & 58,48 & 3310 & 75,88 & 63,17 & 3474 \\
1.500 FTU/kg & $73,64^{*}$ & 60,27 & 3252 & 77,36 & 62,73 & 3444 \\
$4.000 \mathrm{FTU} / \mathrm{kg}$ & $74,05^{*}$ & 61,40 & 3280 & 77,49 & 62,87 & 3448 \\
$6.000 \mathrm{FTU} / \mathrm{kg}$ & $73,39 *$ & 58,06 & 3324 & 76,96 & 62,95 & 3458 \\
$8.000 \mathrm{FTU} / \mathrm{kg}$ & $73,59 *$ & 57,17 & 3329 & 76,79 & 61,19 & 3480 \\
$10.000 \mathrm{FTU} / \mathrm{kg}$ & $74,50^{*}$ & 60,58 & 3356 & 77,27 & 63,91 & 3461 \\
Média & $73,77^{*}$ & 58,17 & 3299 & 77,66 & 62,68 & 3503 \\
CV, \% & 73,63 & 59,16 & 3307 & 77,06 & 62,78 & 3467 \\
* & 1,69 & 3,94 & 1,37 & 2,190 & 3,860 & 1,670 \\
\hline
\end{tabular}

*Média diferente estatisticamente do tratamento controle, pelo teste Dunnett, a 5\% de probabilidade.

${ }^{1}$ Sem suplementação enzimática.

2Efeito quadrático.

Houve efeito quadrático na EMAn em relação aos níveis de inclusão da fitase nas rações, estimando-se a suplementação de 7.727FTU/kg para o melhor aproveitamento da energia da dieta, na fase inicial de criação: $y=-0,000003 x^{2}$ $+0,046363+3182 ; \mathrm{R}^{2}=89,7 \% \quad(\mathrm{P}<0,05)$. De acordo com os resultados, a redução praticada de 85kcal nas dietas suplementadas com fitase foi recuperada pelas aves. Isto pode ter ocorrido por aumento na digestibilidade do amido e/ou por efeito indireto da suplementação enzimática, impedindo que ocorresse reação de saponificação entre os lipídios e os minerais do complexo fitato-mineral, aumentando o aproveitamento energético, segundo Ravindran et al. (2001).

Os resultados mostrados assemelham-se aos de outros trabalhos, em que dietas com baixo Pd e suplementadas com fitase mantêm a EMA adequada para frangos de corte (Ravidran et al., 2001; Panda et al., 2007). Efeito positivo da fitase, na utilização da energia pelas aves, foi também reportado por Camden et al. (2001), ao avaliarem a inclusão de duas enzimas (250, 500 e $1.000 \mathrm{FTU} / \mathrm{kg}$ ) em dietas com milho e soja. O aumento na EMAn estava associado ao acréscimo de $3,5 \%$ no coeficiente de digestibilidade do extrato etéreo, 2,6\% da proteína e 1,4\% do amido.

Shirley e Edwards Junior (2003), porém, constataram melhora linear na EMAn com suplementações de fitase de 0; 93,75; 187,75; 375; 750; 1.500; 3.000; 6.000 e $12.000 F T U / k g$ de ração, ao obterem um acréscimo de $6 \%$ com a inclusão de $12.000 \mathrm{FTU} / \mathrm{kg}$.

A retenção aparente do cálcio e fósforo pelas aves nas fases inicial e de crescimento encontrase na Tab. 7, e nela observa-se maior aproveitamento $(\mathrm{P}<0,05)$ desses minerais pelas aves que receberam ração suplementada com fitase. 
Altos níveis de fitase...

Tabela 7. Coeficientes de retenção aparente de cálcio e fósforo (CRACa, CRAP, \%) nas fases inicial, de 1 a 21 dias, e de crescimento, de 22 a 35 dias, de frangos de corte, submetidos a dietas com diferentes níveis de fitase

\begin{tabular}{lcccc}
\hline & \multicolumn{2}{c}{ Fase inicial } & \multicolumn{2}{c}{ Fase de crescimento } \\
\cline { 2 - 5 } Tratamento & $\begin{array}{c}\text { CRACa } \\
(\%)^{1}\end{array}$ & $\begin{array}{c}\text { CRAP } \\
(\%)^{2}\end{array}$ & $\begin{array}{c}\text { CRACa } \\
(\%)^{3}\end{array}$ & $\begin{array}{c}\text { CRAP } \\
(\%)\end{array}$ \\
\hline Controle & 41,49 & 45,26 & 40,97 & 47,68 \\
$1.500 F T U / k g$ & $48,10^{*}$ & $51,95^{*}$ & $43,79^{*}$ & $60,93^{*}$ \\
$3.000 F T U / k g$ & $51,62^{*}$ & $52,61^{*}$ & $43,79^{*}$ & $61,08^{*}$ \\
$4.500 F T U / k g$ & $51,58^{*}$ & $53,99^{*}$ & $44,02^{*}$ & $61,33^{*}$ \\
$6.000 F T U / k g$ & $54,28^{*}$ & $55,81^{*}$ & $46,28^{*}$ & $62,19^{*}$ \\
$8.000 F T U / k g$ & $52,16^{*}$ & $57,08^{*}$ & $43,46^{*}$ & $62,59^{*}$ \\
$10.000 \mathrm{FTU} / \mathrm{kg}$ & $52,55^{*}$ & $59,01^{*}$ & $43,19^{*}$ & $62,77^{*}$ \\
Média & 50,25 & 53,67 & 43,64 & 59,79 \\
CV, \% & 3,49 & 4,74 & 3,76 & 3,34 \\
\hline
\end{tabular}

*Média diferente estatisticamente do tratamento controle, pelo teste Dunnett, a 5\% de probabilidade.

1,3Efeito quadrático.

${ }^{2}$ Efeito linear.

Na fase inicial, entre os níveis de fitase das rações, estimou-se a inclusão de 5.500 FTU/kg para maximizar a retenção aparente do Ca: $\mathrm{y}=$ $0,0000002 \mathrm{x}^{2}+0,002221 \mathrm{x}+45,5308 ;$ $\mathrm{R}^{2}=80,3 \% \quad(\mathrm{P}<0,05)$. Os resultados dos coeficientes de retenção do $\mathrm{P}$ demonstraram aumento linear $(\mathrm{P}<0,05)$ entre os tratamentos suplementados com a enzima: $\mathrm{y}=0,000857 \mathrm{x}+$ 50,3594; $\mathrm{R}^{2}=99,0 \%$. Apesar de o metabolismo do Ca e o do $\mathrm{P}$ estarem correlacionados, há necessidade de ressaltar que uma série de características ainda não está totalmente esclarecida e ou estabelecida.

Shirley e Edwards Junior (2003) afirmaram que a concentração fisiológica de Ca em aves pode ser mais difícil de ser regulada que a de $\mathrm{P}$, e dietas que contêm mais de 3.000FTU/kg de fitase têm pouco efeito na retenção do Ca. Esses autores observaram efeito linear na retenção do $\mathrm{P}$ com níveis crescentes de fitase, aumentando em até $69 \%$ com a inclusão de $12.000 \mathrm{FTU} / \mathrm{kg}$, em relação à dieta-controle. Entretanto, Manangi e Coon (2008) avaliaram dietas com baixo $\mathrm{P}$ disponível e suplementadas com 250, 500, 750, $1.000,1.500,2.000$ ou $5.000 F T U / k g$ e obtiveram a maior retenção aparente de P com a inclusão de $1.000 \mathrm{FTU} / \mathrm{kg}$ de ração.

De forma semelhante, na fase de crescimento, houve efeito quadrático nos valores de retenção do cálcio $(\mathrm{P}<0,01)$, estimando o maior valor com a inclusão de 5.000FTU/kg: $\mathrm{y}=0,00000009 \mathrm{x}^{2}+$ $0,0009 x+42,233 ; R^{2}=39,3 \%$.
A retenção aparente de fósforo foi maior em todos os tratamentos suplementados com fitase $(\mathrm{P}<0,01)$, atingindo $63 \%$ de retenção com a inclusão de 10.000FTU/kg de ração e representando um acréscimo de $31,7 \%$ em relação ao tratamento controle. Teoricamente, quando as dietas são suplementadas com fitase e com baixo Pd, que consiste em maior proporção de $\mathrm{P}$ fítico por unidade de $\mathrm{P}$ total, ocorre aumento na hidrólise do ácido fítico.

Já se sabe que os teores de cálcio e fósforo na ração para frangos influenciam a utilização do fósforo fítico (Edwards Jr. e Veltmann, 1983; Driver et al., 2005), pois aves que consomem dietas com níveis reduzidos (dentro do limite mínimo) de Ca e Pd inorgânicos possuem maior capacidade para hidrolisar o fitato do que aquelas que recebem níveis altos (Denbow et al., 1995).

\section{CONCLUSÕES}

A suplementação de fitase, a partir de 4.500FTU/kg de ração com redução nutricional e da energia da ração, pode ser usada entre 1 e 35 dias de idade, sem causar prejuízos sobre o desempenho, a digestibilidade dos nutrientes e o aproveitamento da energia, para frangos de corte. Também é possível aumentar a retenção do cálcio e fósforo com altos níveis de fitase. 


\section{REFERÊNCIAS BIBLIOGRÁFICAS}

ANGEL, R.; TAMIN, N.M.; APPLEGATE, T.J.; DHANDU, A.S. et al. Phytic acid chemistry: influence on phytin-phosphorus availability and phytase efficacy. J. Appl. Poult. Res., v.11, p.471-480,2002.

CAMDEN, B.J.; MOREL, P.C.H.; THOMAS, D.V. et al. Effectiveness of exogenous microbial phytase in improving the bioavailabilities of phosphorus and other nutrients in maize-soya-bean meal diets for broilers. Anim. Sci., v.73, p.289-297, 2001.

COBB-VANTRESS broiler nutrition guide. Broiler nutrition supplement. Guapiaçu-SP: Cobb-Vantress Brasil, Ltda, 2004.

COWIESON, A.J.; ACAMOVIC, T.; BEDFORD, M.R. Phytic acid and phytase: implications for protein utilization by poultry. Poult. Sci., v.85, p.878-885, 2006.

DARI, R.L. Utilização de fitase na alimentação de aves. In: CONFERÊNCIA APINCO DE CIÊNCIA E TECNOLOGIAS AVÍCOLAS, 2004, Santos. Anais... Santos: FACTA, 2004. p.127-143.

DENBOW, D.M.; RAVINDRAN, V.; KORNEGAY, E.T. et al. Improving phosphorous availability in soyabean meal for broilers by supplemental phytase. Poult. Sci., v.74, p.1831- 1842, 1995.

DRIVER, J.P.; PESTI, G.M.; BAKALLI, R.I. et al. Effects of calcium and nonphytate phosphorus concentrations on phyatse efficacy in broilers chicks. Poult. Sci., v.84, p.1406-1417, 2005.

EDWARDS JUNIOR, H.M.; VELTMANN, J. The role of calcium and phosphorus in the etiology of tibial dyscondroplasia in young chicks. J. Nutr., v.113, p.1568-1575, 1983.

FERREIRA, D.F. Sistema para análise de variância para dados balanceados - SISVAR 4.1. Lavras: UFLA, 2000. Software.

FUKAYAMA, E.H.; SAKOMURA, N.K.; DOURADO, L.R.B.D. et al. Efeito da suplementação de fitase sobre o desempenho e a digestibilidade dos nutrientes em frangos de corte. Rev. Bras. Zootec., v.37, p.629-635, 2008

LOTT, J.N.A.; OCKENDEN, I.; RABOY, V. et al. Phitic acid on phosphorus crop seed and fruit: a global estimate. Seed Sci. Res., v.10, p.11-33, 2000.
MANANGI, M.K.; COON, C.K. Phytate phosphorus hidrolysis in broilers in response to dietary phytase, calcium, and phosphurus concntrations. Poult. Sci., v.87, p.1577-1586, 2008

MULLANEY, E.J.; DALY, C.B.; ULLAH, A.H. Advances in phytases research. Adv. Appl. Microbiol., v.47, p.157-199, 2000.

PANDA, A.K.; RAO, S.V.R.; RAJU, M.V.L.N. et al. Performance of broiler chickens fed low non phytate phosphorus diets supplemented with microbial phytase. J. Poult. Sci., v.44, p.258-264, 2007.

PUCCI, L.E.A.; RODRIGUES, P.B.; FREITAS, R.T.F. et al. Níveis de óleo e adição de complexo enzimático na ração de frangos de corte. Rev. Bras. Zootec., v.32, p.909-917, 2003.

RAVINDRAN, V.; CABAHUG, S.; RAVINDRAN, G. et al. Influence of microbial phytase on apparent ileal amino acids digestibility of feedstuffs for broilers. Poult. Sci., v.78, p.699-706, 1999.

RAVINDRAN, V.; SELLE, P.H.; RAVINDRAN, G. et al. Microbial phytase improves performance, apparent metabolizable energy, and ileal amino acid digestibility of broilers fed a lysine-deficient diet. Poult. Sci., v.80, p.338- 344, 2001

RODRIGUES, P.B.; MARTINEZ, R.S.; FREITAS, R.T.F. et al. Influência do tempo de coleta e metodologias sobre a digestibilidade e o valor energético de rações para aves. Rev. Bras. Zootec., v.34, p.882-889, 2005.

ROSTAGNO, H.S.; ALBINO, L.F.T.; DONZELE, J.L. et al. Tabelas brasileiras para aves e suínos: composição de alimentos e exigências nutricionais. 2.ed. Viçosa, MG: UFV, 2005. 186 p.

SELLE, P.H.; RAVINDRAN, G. Microbial phytase in poultry nutrition. Anim. Feed Sci. Technol., v.135, p.141, 2007.

SHIRLEY, R.B.; EDWARDS JUNIOR, J.A. Graded levels of phytase past industry standards improves broilers performance. Poult. Sci., v.82, p.671-680, 2003.

SILVA, D.J.; QUEIROZ, A.C. Análises de alimentos: métodos químicos e biológicos. Viçosa, MG: UFV, 2002. 235p. 